Relations industrielles

Industrial Relations

\title{
The French Labor Courts : Judgment by Peers, by William H. McPherson and Frederic Meyers, Institute of Labor and Industrial Relations, University of Illinois, Urbana, 1966. 104 pages.
}

\section{Gilles Richard}

Volume 22, numéro 1, 1967

URI : https://id.erudit.org/iderudit/027774ar

DOI : https://doi.org/10.7202/027774ar

Aller au sommaire du numéro

Éditeur(s)

Département des relations industrielles de l'Université Laval

ISSN

0034-379X (imprimé)

1703-8138 (numérique)

Découvrir la revue

Citer ce compte rendu

Richard, G. (1967). Compte rendu de [The French Labor Courts : Judgment by Peers, by William H. McPherson and Frederic Meyers, Institute of Labor and Industrial Relations, University of Illinois, Urbana, 1966. 104 pages.] Relations industrielles / Industrial Relations, 22(1), 142-142.

https://doi.org/10.7202/027774ar

Tous droits réservés @ C Département des relations industrielles de l'Universite Laval, 1967
Ce document est protégé par la loi sur le droit d'auteur. L'utilisation des services d'Érudit (y compris la reproduction) est assujettie à sa politique d'utilisation que vous pouvez consulter en ligne.

https://apropos.erudit.org/fr/usagers/politique-dutilisation/ 
un intérêt particulièrement grand aux tomes deux et trois.

Inutile d'insister outre mesure en recommandant cet excellent ouvrage. Je suis certain qu'il saura s'imposer par lui-même. Je veux toutefois signaler l'importance pour les Canadiens français d'utiliser le volume traduit et adapté par monsieur Sylvain, car dans un marché aussi limité que le nôtre, il n'y a peut-être pos de place présentement pour plus d'un ourrage sur le sujet.

\section{Bertrand BELZILE}

The Suburban Society, par S.D. Clark, University of Toronto Press, Toronto Ontario, 1966,229 pages.

"There is no essential difference between new society of the suburbs and any other new society in terms of the kinds of forces which produced it $\mathbf{~ . ~}$

Tel est l'essentiel de la thèse que le sociologue torontois S.D. Clark soutient pour l'explication des sociétés banlieusardes. Cetto image semble aller à l'encontre de celle, plus communément admise, de Fourastié et de Riesman.

En effet, ce livre défie nos idées un peu stéréotypées au sujet des tendances de lo société moderne. Le professeur s'attache surtout ici aux grandes banlieues développées très rapidement qui, dit-il, ne démontrent pas les caractéristiques qu'on leur a attribuées jusqu'à maintenant. Pour lui, le banlieusard s'y est installé parce que le manque d'espace l'a forcé de quitter la ville. Ces centres, ayont eu un début difficile ont vite emprunté les caractéristiques urbaines. C'est là un des exemples les plus frappants des changements sociaux rapides de notre siècle.

$\mathrm{Ce}$ volume sera d'une grande utilité pour tous ceux qui s'intéressent à la ville, d̀ sa nature et à son développement.

\section{Poul GUY}

\section{The French Labor Courts: Judgment by} Peers, by William $\mathrm{H}$. McPherson and Frederic Meyers, Institute of Labor and Industrial Relations, University of Illinois, Urbana, 1966.104 pages.

Ce volume, à la fois onalytique et descriptif, vise à mettre en lumière le rôle et le fonctionnement des tribunaux du travail en France, tout en espérant que les outres pays, dont les Etats-Unis, bénéficient de cette expérience.

Après un bref aperçu historique, les auteurs nous présentent la structure d'organisation, le champ de la juridiction et les règles de procédure de ces tribunaux du travail.

Contrairement à ce que l'on rencontre dons la plupart des autres pays où il existe de semblables tribunaux, les juges ne sont pos nommés d'office par un organisme gouvernemental, mais plutôt élus en nombre égal parmi les représentants patronaux et syndicoux et, même parmi les travailleurs du rang. Leur mandat est d'une durée de six ans et, ils exercent leurs fonctions exclusivement au sein de la catégorie qu'ils représentent.

Le tribunal est habilité à rendre jugement sur l'ensemble des conflits de droit, qui peuvent survenir entre employeur et employé, soit à partir de la violation du contrat individuel de travail, de la législation, de la convention collective, ou tout simplement des usages et des coutumes dans l'industrie. Tout employeur ou tout employé peut recourir à ce tribunal, qu'il soit ou non assujetti d̀ une convention collective.

Une partie importante du présent ouvrage tente d'analyser et d'évaluer le fonctionnement actuel de ces tribuncux à partir de l'expérience quotidienne de la Cour de Paris. On y présente une étude des différentes causes, une oppréciation des divers documents disponibles, des observations personnelles sur les divers types de sessions et, de plus, une foule de renseignements recueillis auprès des juges, des représentants patronaux et syndicaux, et autres personnes en contact avec la Cour.

Cette brève appréciation de l'expérience française et des résultats positifs obtenus est sûrement de nature à favoriser l'évolution et l'amélioration du système nord-américain vers la création de véritables tribunaux du trovail répondant aux besoins de notre société. La parution de cet ouvrage ne peut que stimuler cet espoir et réjouir tous ceux qui luttent pour l'amélioration de notre système de relations industrielles.

\section{Gilles RICHARD}

Compulsory Arbitration: Panacea Or Millstone?, by Harold S. Roberts, University of Hawaii, Industrial Relations Center, December 1965, 162 poges.

L'auteur exprime ainsi le but de son livre: "What we have done here is to pre- 